\title{
PELAKSANAAN TANGGUNG JAWAB TERHADAP PERUSAHAAN YANG TIDAK MENDAFTARKAN PEKERJANYA MENJADI PESERTA BPJS DI KOTAMADYA DENPASAR ${ }^{1}$
}

\author{
Oleh: \\ Imelda Sutoyo ${ }^{2}$ \\ I Made Sarjana ${ }^{3}$ \\ I Nyoman Mudana4 \\ Bagian Hukum Bisnis, Fakultas Hukum, Universitas Udayana
}

\begin{abstract}
ABSTRAK
Pelayanan kesejahteraan merupakan rangkaian pemberian tunjangan dan fasilitas dalam bentuk tertentu kepada kepada pekerja diluar gaji, biasanya berupa jaminan sosial. Kewajiban perusahaan untuk memberikan jaminan sosial kepada pekerjanya yakni dengan mendaftarkan dirinya dan pekerjanya menjadi peserta program Badan Penyelenggara Jaminan Sosial(BPJS) Ketenagakerjaan telah diatur dalam Undang-Undang(UU). Namun dalam realitanya di Kotamadya Denpasar masih terdapat \pm 2000 perusahaan yang tidak memberikan jaminan sosial kepada pekerjanya. Metode penelitian yang digunakan untuk mengkaji dan menganalisis permasalahan tersebut bersifat yuridis empiris dan diketahui bahwa faktor-faktor penyebab perusahaan di Kotamadya Denpasar tidak mendaftarkan pekerjanya dalam program BPJS adalah kurangnya kesadaran dari pihak perusahaan mengenai pentingnya BPJS hingga karena kurangnya kesadaran pekerja akan pentingnya menjadi peserta BPJS. Diharapkan Dinas Tenaga Kerja Kotamadya Denpasar memberikan sosialisasi mengenai informasi yang lebih lengkap kepada para pemilik UKM dan manajemen perusahaan agar dapat mendaftarkan pekerjanya sebagai peserta BPJS.
\end{abstract}

\section{Kata kunci : Tanggung Jawab, Perusahaan, BPJS, Kotamadya Denpasar}

\footnotetext{
1 Tulisan ini merupakan tulisan ilmiah dari ringkasan skripsi.

2 Imelda Sutoyo adalah mahasiswa Fakultas Hukum, Universitas Udayana, korespondensi : imeldasutoyo@gmail.com.

3 I Made Sarjana adalah Dosen Fakultas Hukum, Universitas Udayana, sebagai penulis II.

${ }^{4}$ I Nyoman Mudana adalah Dosen Fakultas Hukum, Universitas Udayana, sebagai penulis III.
} 


\begin{abstract}
Welfare services are a series of benefits and facilities provided in certain forms to employees besides salary, usually in the form of social security. The obligation of companies to provide social security to their workers, namely by registering them as participants in the program of the Social Security Organizing Agency (BPJS), has been regulated in the Law (UU). But in reality, in the Municipality of Denpasar, there are still approximately 2000 companies that do not provide social security to their workers. The research method used to examine and analyze these issues is juridical empirical method and it is known that the factors that cause the companies in the Municipality of Denpasar not to register their workers in the BPJS program are the lack of awareness from the company regarding the importance of BPJS due to lack of awareness from the workers of the importance of becoming BPJS participants. It is expected that the Denpasar City Manpower Office will provide more complete information to SME owners and company management to be able to register their workers as BPJS participants.
\end{abstract}

\title{
Keywords: Responsibility, Company, BPJS, Municipality of Denpasar
}

\section{PENDAHULUAN}

\subsection{LATAR BELAKANG}

Didalam penegakan hukum menjalankan perintah peraturan dan perundangan, Badan Penyelenggara Jaminan Sosial (BPJS) Ketenagakerjaan telah merekrut karyawan khusus sebagai petugas yang mengawasi dan memeriksa perusahaan-perusahaan yang melanggar peraturan dan perundangan terkait perusahaan yang tidak mengikutsertakan dirinya dan pekerjanya menjadi peserta BPJS Ketenagakerjaan. Selain petugas pengawas dan pemeriksa BPJS Ketenagakerjaan, peran aparat penegak hukum dan pemerintah Kotamadya Denpasar juga sangat diharapkan dalam membantu BPJS Ketenagakerjaan untuk menindak lanjuti perusahaan-perusahaan yang melanggar ketentuan perundangan terkait kewajiban perusahaan mengikutsertakan dirinya dan pekerjanya menjadi peserta program BPJS Ketenagakerjaan. 
Perkembangan industri yang terjadi di Kotamadya Denpasar membuat banyak dari pelaku usaha merekrut tenaga kerja untuk menjalankan kegiatan usahanya. Para tenaga kerja tersebut sebenarnya memiliki hak terhadap kesejahteraan mereka, dimana salah satu hak dari tenaga kerja di Indonesia adalah mendapatkan jaminan dari BPJS Ketenagakerjaan. Fenomena yang terjadi di Kotamadya Denpasar sering kali beberapa perusahaan tidak mengikuti aturan yang berlaku seperti seluruh karyawan yang harus terdaftar sebagai anggota BPJS. Usaha tersebut harus mentaati peraturan yang berlaku yaitu Pasal 35 Undang - Undang no 13 Tahun 2003 tentang ketenagakerjaan yang berbunyi :

"Pemberi kerja sebagaimana dimaksud dalam ayat (1) dalam mempekerjakan tenaga kerja wajib memberi kan perlindungan yang mencakup kesejahteraan, keselamatan, dan kesehatan baik mental maupun fisik tenaga kerja".

Berdasarkan Undang-Undang (UU) Republik Indonesia Nomor 24 Tahun 2011 Tentang Badan Penyelenggara Jaminan Sosial menyatakan bahwa BPJS Ketenagakerjaan merupakan salah satu jaminan atas kesehatan dan keselamatan bekerja yang dipelopori oleh pemerintah. Namun dalam realitanya di Kotamadya Denpasar masih terdapat \pm 2000 perusahaan yang tidak memberikan jaminan sosial kepada pekerjanya ${ }^{5}$. Hal tersebut disebabkan oleh enggannya para pelaku usaha untuk mengeluarkan dana lebih untuk iuran BPJS Ketenagakerjaan hingga masalah internal perusahaan tersebut. Tanggung jawab perusahaan yang secara klasik dimaknai berorientasi semata pada profit oriented demi kelangsungan kegiatan

5 Putu Yudi, 2016, http://www.balipost.com/asdas/2745622, diakses pada 22 Agustus 2017. 
usaha perusahaan. ${ }^{6}$ Akan tetapi, semua perusahaan tersebut perlu mendapatkan peringatan atau bahkan penegakan hukum agar hak hak pekerja dapat diperjuangkan sesuai dengan peraturan yang berlaku.

\subsection{RUMUSAN MASALAH}

Adapun permasalahan yang dapat peneliti rumuskan adalah

1. Apa faktor-faktor penyebab perusahaan di Kotamadya Denpasar tidak mendaftarkan pekerjanya dalam kepesertaan BPJS?

2. Bagaimana penerapan sanksi hukum terhadap perusahaan yang tidak mendaftarkan pekerjanya menjadi peserta dalam program BPJS ketenagakerjaan di Kotamadya Denpasar?

\subsection{TUJUAN PENELITIAN}

Tujuan dari penelitian penelitian ini adalah untuk menganalisa implementasi Undang-Undang no 13 Tahun 2003 Tentang Tenaga Kerja terutama pasal 35 tentang kesejahteraan pekerja dan UndangUndang no 24 Tahun 2011 tentang BPJS serta untuk menganalisa penerapan sanksi mengenai penegakan hukum terhadap perusahaan yang tidak mendaftarkan pekerjanya menjadi peserta dalam program BPJS ketenagakerjaan di Kotamadya Denpasar.

\section{ISI MAKALAH}

\subsection{METODE PENELITIAN}

Pembahasan permasalahan yang ada dalam skripsi ini penulis menggunakan metode penelitian yuridis empiris. Penelitian ini menggunakan penelitian hukum empiris yaitu suatu penelitian yang

${ }^{6}$ Ida Ayu Sukihana dan I Gede Agus Kurniawan , "Tanggung Jawab Perusahaan dari Profit Menuju Stakeholders Oriented Studi CSR di Tabanan", Artikel dalam Jurnal Kertha Patrika, 2016, Vol. 38, No.1, h196 
melakukan dengan observasi atau penelitian dengan secara langsung terjun kelapangan guna untuk mendapatkan kebenaran yang akurat dalam penulisan skripsi. ${ }^{7}$

\subsection{HASIL DAN PEMBAHASAN}

\subsubsection{Faktor Penyebab Perusahaan Tidak Mendaftarkan Pekerjanya Dalam Kepesertaan BPJS Di Denpasar}

Menurut Undang-undang Nomor 24 Tahun 2011 tentang Badan Penyelenggara Jaminan Sosial, jaminan sosial adalah salah satu bentuk perlindungan sosial untuk menjamin seluruh rakyat agar dapat memenuhi kebutuhan dasar hidupnya yang layak. ${ }^{8}$

Perlindungan hukum terhadap tenaga kerja berlaku di seluruh wilayan Indonesia, termasuk di Kotamadya Denpasar. Berbagai perkembangan industri di Kotamadya Denpasar mempengaruhi pola produksi dan distribusi masyarakat, hal ini membawakan dampak berbagai positif ataupun negatif pada perekonomian di masyarakat Kotamadya Denpasar dengan kaitannya dengan kenaikan kebutuhan hidup masyarakat. Maka dalam itu perusahan banyak sekali berbagai perusahaan menawarkan pekerjaannya tetapi perusahaan harus patuh dan menjamin perlindungan hokum kepada karyawannya seperti membayar upah kepada pekerja/buruh sesuai dengan ketentuan yang berlaku sebagai kewajiban para pengusaha ${ }^{9}$. Apa itu perlindungan hukum? Sebagai makhluk sosial maka sadar atau tidak sadar manusia selalu melakukan perbuatan hokum

\footnotetext{
${ }^{7}$ Soerjono Soekanto.2015.Penelitian Hukum Normatif Suatu Tinjauan Singkat.Rajawali Pers. Jakarta.h.:52

8 Iman Soepomo, 2015, Pengantar Hukum Perburuhan, Djambatan, Jakarta, h. 1

${ }^{9}$ Asri Wijayanti, 2010, Hukum Ketenagakerjaan Pasca Reformasi, h.45
} 
(rechtshandeling) dan hubungan hukum (rechtsbetrekkingen). ${ }^{10}$ Suatu hubungan hukum akan memberikan hak dan kewajiban yang telah ditentukan oleh peraturan perundang-undangan, sehingga apabila dilanggar akan mengakibatkan pihak pelanggar dapat dituntut di pengadilan. ${ }^{11}$ Hadjon berpendapat bahwa, perlindungan hukum adalah suatu tindakan untuk melindungi atau memberikan pertolongan kepada subyek hukum, dengan menggunakan perangkat-perangkat hukum. ${ }^{12}$

Berdasarkan wawancara dengan Kabid BPJS Ketenagakerjaan Bapak Ziki Nihwati menyatakan bahwa praktek dilapangan masih banyak perusahaan-perusahaan yang belum tahu mengenai perubahan ini, alhasil mereka tidak mendaftarkan para karyawannya ke BPJS Kesehatan dan BPJS Ketenagakerjaan yaitu sebagai lembaga yang berwenang menyelenggarakan hak-hak para karyawan seperti kesehatan dan dana pensiun. Jikalau seperti itu maka yang patut dipersalahkan adalah para legal officer dan HRD staff karena tidak aware terhadap perubahan peraturan perundang-undangan di bidang ketenagakerjaan sebagai salah satu tugas dan kewajibannya di suatu perusahaan.

Namun dalam kasus pada perusahaan di Kotamadya Denpasar, diketahui bahwa perusahaan tersebut mayoritas adalah perusahaan yang memiliki skala kecil, dimana hanya memperkerjakan karyawan-karyawan lepas dengan tidak berdasarkan perjanjian kerja. Pada dasarnya peraturan di bidang jaminan sosial khususnya berkaitan dengan Jaminan kesehatan

10 R. Soeroso, 2006, Pengantar Ilmu Hukum, Sinar Grafika, Jakarta, h. 49

11 Soedjono Dirjosisworo, 2001, Pengantar Ilmu Hukum, PT. RajaGrafindo Persada, Jakarta, h. 131

12 Philipus M. Hadjon, 2011, Pengantar Hukum Administrasi Indonesia, Gajah Mada University Press, Yogyakarta, h. 10. 
tidak membedakan kualifikasi pemberi kerja yang wajib mendaftarkan pekerjanya baik BPJS Kesehatan maupun BPJS Ketenagakerjaan. Kondisi ini tampak dalam Pasal 14 yang menyatakan bahwa setiap orang yang termasuk orang asing yang bekerja di Indonesia paling singkat 6 (enam) bulan wajib menjadi peserta program jaminan sosial. Adapun yang dimaksud dengan program Jaminan sosial ini tentunya adalah Jaminan Ketenagakerjaan dan Jaminan Kesehatan.

Pasal 11 Peraturan BPJS No.1 Tahun 2014 menyatakan pendaftaran BPJS Kesehatan ini dapat dilakukan secara sendirisendiri maupun kelompok. Pasal 15 Peraturan BPJS No.1 Tahun 2014 Jo Pasal 11 ayat 1 Perpres No.12 Tahun 2013 ditekankan kembali bahwa Pendaftaran peserta Jaminan Kesehatan bagi Pekerja Penerima Upah harus dilakukan oleh pemberi kerja yang dalam hal ini tentu saja Perusahaan yang bersangkutan, dilakukan secara berkelompok melalui entitasnya kepada BPJS Kesehatan.

Akan tetapi sebagai penawar ketentuan tersebut, penting diperhatikan bahwa Pasal 15 di atas bukanlah suatu kewajiban karena dalam Pasal 16 ditentukan bahwa dalam hal Pemberi Kerja secara nyata-nyata tidak mendaftarkan Pekerjanya kepada BPJS Kesehatan, pekerja yang bersangkutan berhak mendaftarkan dirinya sebagai peserta Jaminan Kesehatan. Nah hal ini berarti jika Pemberi Kerja tidak mendaftarkan para pekerjanya, maka kewajiban bagi para pekerja-pekerja tersebut mendaftarkan dirinya sendiri. Dengan kata lain Peraturan tidak mewajibkan para pemberi kerja untuk mendaftarkan para pekerjanya atas Jaminan Kesehatan pada BPJS Kesehatan. Anda dapat menunjukan dasar hukum ini untuk membantah klaim denda yang diajukan oleh Dinas Ketenagakerjaan. 
Salah satu faktor yang menyebabkan perusahaan tidak mengikutsertakan karyawannya dalam program BPJS adalah karena tingkat pendidikan dan kesadaran hukum dari pekerjanya masih rendah. Jika tingkat pendidikan dan kesadaran hukum dari pekerjanya sudah baik, maka pekerja tersebut dapat mempermasalahkan keputusan perusahaannya tidak mengikutsertakan pegawai dalam program BPJS, karena program BPJS merupakan program wajib dari pemerintah Republik Indonesia.

BPJS Ketenagakerjaan adalah program pemerintah yang memberikan jaminan sosial ekonomi untuk setiap pekerja indonesia, setiap perusahaan wajib mendaftarkan karyawannya untuk menjadi peserta dari BPJS ketenagakerjaan dengan iuran bulanan yang sebagian ditanggung oleh perusahaan. Jaminan social yang dimaksud terdiri atas jaminan berupa uang yang meliputi jaminan kecelakaan kerja, jaminan kematian dan jaminan hari tua serta jaminan berupa pelayanan yaitu jaminan pemeliharaan kesehatan.

UU Ketenagakerjaan tidak memberikan pengertian tentang pensiun. Penafsiran oten- tik mengenai pensiun justru ditemukan dalam Undang-Undang Nomor 43 tahun 1999 tentang Kepegawaian (UU Kepegawaian) yang mendefinisikan pensiun sebagai jaminan hari tua dan ba- las jasa terhadap pegawai negeri yang telah bertahuntahun mengabdikan dirinya kepada negara. UU Kepegawaian mempersamakan uang pensiun dengan jaminan hari tua.

Sulit mempersamakan definisi pensiun dalam Undang-Undang Kepegawaian dengan makna yang tersirat dalam pensiun menurut UU Ketenagakerjaan. Dalam UU Ketenagakerjaan jaminan hari tua adalah lembaga tersendiri yang keberadaannya dipisahkan dengan jaminan pensiun dan pesangon. Pasal 167 ayat (6) UU 
Ketenagakerjaan secara tegas menyatakan bahwa hak atas manfaat pensiun tidak menghilangkan hak pekerja/buruh atas jaminan hari tua yang bersi- fat wajib sesuai dengan peraturan perundangan yang berlaku. Konsep pensiun yang ada dalam Undang-Undang Kepegawaian memang hanya cocok diterapkan bagi pegawai negeri sipil, dan bukan bagi buruh/pekerja. ${ }^{13}$

Salah satu perusahaan sampel yang tidak mendaftarkan pegawainya di BPJS adalah Umico Dentsply, yang merupakan salah satu perusahaan yang menyediakan produk farmasi untuk kesehatan gigi dan operasional para dokter gigi. Perusahaan ini memiliki pusat di Bandung, dimana kantor cabang di Bali merupakan kantor cabang yang membantu penjualan di daerah Bali dan NTB. Hanya terdapat dua belas orang karyawan yang bekerja di perusahaan ini, dimana kedua belas karyawan tersebut tidak didaftarkan perusahaan untuk program BPJS ketenagakerjaan. Hal tersebut sesuai dengan hasil wawancara dengan salah satu pekerja Umico Dentsply yaitu Ibu Keke dimana menyatakan bahwa perusahaan beroperasi homebased, dimana kantor mereka adalah rumah yang disewa oleh pihak kantor pusat Bandung.

Tingkat pendidikan dari pekerja di Umico Dentsply adalah tamatan SMA untuk bagian administrasi, dan tamatan S1 untuk bagian sales. Hal tersebut menyebabkan kesadaran hukum dari pekerja di Umico Dentsply memang tidak tinggi, sehingga pekerja merasa baik - baik saja saat perusahaan tidak mendaftarkan pekerja

13 Ari Hernawan, "Keberadaan Uang Pesangon Dalam Pemutusan Hubungan Kerja Demi Hukum di Perusahaan yang Sudah Menyelenggarakan Program Jaminan Pensiun", Artikel dalam Jurnal Kertha Patrika, 2016, Vol. 38, No.1, h. 7 
dalam keanggotaan BPJS ketenagakerjaan. Selain itu faktor ekonomi membuat pekerja tidak ingin memprotes perusahaan karena tidak mendaftarkan mereka pada BPJS ketenagakerjaan. Jika perusahaan mendaftarkan BPJS para pegawainya, maka dana BPJS tersebut akan dipotong langsung dari gaji pegawai tersebut. Maka dari itu pegawai pada perusaahan Umico Dentsply yang beroperasi di Kotamadya Denpasar ini tidak mempermasalahkan perusahaan karena tidak mendaftarkan karyawannya di BPJS Ketenagakerajaan.

Jika terjadi kecelakaan kerja, maka hal tersebut akan ditanggung oleh masing - masing karyawan, dimana perusahaan hanya membantu memberi santunan jika terjadi hal - hal yang tidak diinginkan selama bekerja. Besaran santunan tersebut juga tidak memiliki nilai pasti, karena santunan tersebut akan ditentukan oleh pihak manajemen perusahaan sesuai dana perusahaan yang tersedia.

\subsubsection{Sanksi Hukum Terhadap Perusahaan Yang Tidak Mendaftarkan Pekerjanya Menjadi Peserta Dalam Program Bpjs Ketenagakerjaan Di Kotamadya Denpasar}

Sampai saat ini, data yang masuk di kantor BPJS di Kotamadya Denpasar, baru ada sekitar 60 persen perusahaan yang mendaftarkan para pekerjanya menjadi peserta BPJS ketenagakerjaan. Sekitar 40 persen dari total perusahaan yang terdata di Dinas Tenaga Kerja akan secepatnya akan ditelusuri untuk diminta pertanggung jawabannya terkait kewajiban mendaftarkan karyawannya menjadi peserta BPJS. Penertiban perusahaan yang tidak mendaftarkan karaywannya di BPJS sudah sering dilakukan. Hal tersebut mulai dari pendataan perusahaan yang belum 
mendaftarkan karyawannya ke program BPJS, dan topik lain yang masih berkaitan dengan BPJS Ketenagakerjaan. Sampai harus menggerakkan semua karyawan untuk turun ke jalan menyisir perusahaan-perusahaan dan memberikan surat imbauan. "Ada perusahaan yang memang tidak mendaftarkan karyawannya, karena termasuk perusahaan kecil dan belum memberikan gaji sesuai UMK. Tapi pembantu rumah tangga dan pekerja industri rumahan wajib ikut serta BPJS. Karena termasuk dalam pekerja, maka wajib ikut serta dan pekerja di Indonesia harus dilindungi hak-haknya.

Perusahaan wajib mendaftarkan BPJS Kesehatan karyawan. Hal ini juga disebutkan dalam Undang-Undang Nomor 24 Tahun 2011 tentang Badan Penyelenggara Jaminan Sosial, dikarenakan BPJS Kesehatan merupakan salah satu bentuk jaminan sosial yang diatur oleh pemerintah. Undang-undang ini pun mengatur tentang sanksi perusahaan yang tidak mendaftarkan BPJS kesehatan karyawan. Pasal 17 ayat 1 dan 2 menyatakan bahwa pemberi kerja yang tidak melaksanakan anjuran pemerintah tentang BPJS kesehatan akan dikenai sanksi administratif berupa:

1. Teguran tertulis;

2. Denda; dan/atau

3. Tidak mendapat pelayanan publik tertentu.

Sebagai contoh, perusahaan di Kota Semarang yang hendak mengajukan izin usaha ke Dinas Penanaman Modal Dan Pelayanan Terpadu Satu Pintu (DPMPTSP) Kota Semarang harus sudah terdaftar sebagai peserta BPJS Kesehatan. Jika perusahaan belum mendaftarkan pekerjanya ke BPJS Kesehatan, maka perusahaan tersebut akan dilaporkan ke BPJS Pusat dan menerima surat teguran. 
Selain itu, Pasal 55 UU BPJS turut mengatur sanksi bagi Pemberi Kerja yang melanggar ketentuan tentang pembayaran dan penyetoran iuran jaminan sosial, yaitu dapat dipidana dengan pidana penjara paling lama 8 (delapan) tahun atau pidana denda paling banyak Rp 1.000.000.000 (satu miliar rupiah).

Berkenaan dengan denda bagi perusahaan, perlu diperhatikan bahwa denda yang dimaksud tersebut adalah denda keterlambatan pembayaran iuran yang besarnya $2 \%$ per bulan dari total iuran yang tertunggak paling banyak untuk waktu 3 (tiga) bulan, yang dibayarkan bersamaan dengan total iuran yang tertunggak oleh Pemberi Kerja (Pasal 35 ayat 4 Peraturan BPJS No.1 Tahun 2014), sehingga bukan merupakan denda karena belum mendaftar BPJS Kesehatan. Namun Anda perlu memeriksa terlebih dahulu apakah memang benar Perusahaan Anda sebelumnya belum mendaftar atau belum. Karena tidak ada sanksi atau denda spesifik yang diatur dalam peraturan mengenai Jaminan Kesehatan apabila pemberi kerja (Perusahaan) tidak mendaftarkan karyawannya ke BPJS Kesehatan.

\section{PENUTUP}

\subsection{Kesimpulan}

1. Faktor-faktor penyebab perusahaan di Kotamadya Denpasar tidak mendaftarkan pekerjanya dalam kepesertaan BPJS adalah skala usaha yang kecil sehingga perusahaan tidak mendaftarkan pekerjanya, kurangnya kesadaran dari pihak perusahaan mengenai pentingnya BPJS hingga karyawan yang enggan mengikuti program BPJS akibat nilai angsuran yang dikatakan memberatkan

2. Penerapan sanksi hukum terhadap perusahaan yang tidak mendaftarkan pekerjanya menjadi peserta dalam program 
BPJS ketenagakerjaan di Kotamadya Denpasar adalah teguran administratif seperti penutupan izin usaha hingga pelaporan tindak pidana dengan pidana penjara paling lama 8 (delapan) tahun atau pidana denda paling banyak Rp 1.000.000.000 (satu miliar rupiah).

\subsection{Saran}

1. Diharapkan Dinas Tenaga Kerja Kotamadya Denpasar memberikan sosialisasi mengenai informasi yang lebih lengkap kepada para pemilik UKM dan manajemen perusahaan agar dapat mendaftarkan pesertanya sebagai karyawan. Hal tersebut dilakukan dengan harapan para pekerja mendapatkan perlindungan hukum berupa hak dasar yang sesuai dengan peraturan yang berlaku.

2. Para pekerja sector informal hendaknya dapat mendaftarkan secara mandiri kepada BPJS jika pemeilik usaha tidak mau untuk melaksanakan kewajibannya dalam mendaftarkan karyawannnya di BPJS. Dinas Tenaga Kerja Kotamadya Denpasar hendaknya melakukan penerapan sanksi bagi perusahaan yang tidak mendaftarkan karyawannya di BPJS Ketenagakerjaan tanpa diskriminatif. 


\section{Daftar Pustaka}

\section{A. Buku}

Asri Wijayanti. 2010. Hukum Ketenagakerjaan Pasca Reformasi.

Iman Soepomo. 2015. Pengantar Hukum Perburuhan. Djambatan. Jakarta. h.1

Philipus M. Hadjon. 2011. Pengantar Hukum Administrasi Indonesia. Gajah Mada University Press. Yogyakarta.

R. Soeroso. 2006. Pengantar Ilmu Hukum. Sinar Grafika. Jakarta. hal. 49.

Soedjono Dirjosisworo. 2001. Pengantar Ilmu Hukum. PT. RajaGrafindo Persada. Jakarta.

Soerjono Soekanto.2015.Penelitian Hukum Normatif Suatu Tinjauan Singkat.Rajawali Pers. Jakarta

\section{B. Jurnal/Makalah}

Ari Hernawan, "Keberadaan Uang Pesangon Dalam Pemutusan Hubungan Kerja Demi Hukum di Perusahaan yang Sudah Menyelenggarakan Program Jaminan Pensiun", Artikel dalam Jurnal Kertha Patrika, 2016, Vol. 38, No.1

Ida Ayu Sukihana dan I Gede Agus Kurniawan , "Tanggung Jawab Perusahaan dari Profit Menuju Stakeholders Oriented Studi CSR di Tabanan", Artikel dalam Jurnal Kertha Patrika, 2016, Vol. 38, No.1

\section{Internet}

Putu Yudi. 2016. http://www.balipost.com/asdas/2745622. diakses pada 22 Agustus 2017.

\section{Peraturan Perundang-undangan}

Indonesia, Undang-Undang Nomor 13 Tahun 2003 Tentang Ketenagakerjaan, Lembaran Negara Republik Indonesia Tahun 2003 Nomor 39, Tambahan Lembaran Negara Republic Indonesia Nomor 4279. 
Indonesia, Undang-Undang Nomor 24 Tahun 2011 Tentang Badan Penyelenggara Jaminan Sosial, Lembaran Negara Republik 13 Indonesia Tahun 2011 Nomor 116, Tambahan Lembaran Negara Republik Indonesia Nomor 5256.

Indonesia, Peraturan Badan Penyelenggara Jaminan Sosial Kesehatan Nomor 1 Tahun 2014 tentang Penyelenggara Jaminan Kesehatan (Berita Negara Republik Indonesia Tahun 2014 Nomor 1) 